\title{
Short Sales, Price pressure, and the Stock Price Response to Convertible Bond Calls
}

\author{
Bechmann, Ken
}

Document Version

Final published version

Publication date:

2003

License

CC BY-NC-ND

Citation for published version (APA):

Bechmann, K. (2003). Short Sales, Price pressure, and the Stock Price Response to Convertible Bond Calls. Centre for Analytical Finance. Aarhus School of Business. University of Aarhus. Working Paper Series / Centre for Analytical Finance No. 164

Link to publication in CBS Research Portal

\footnotetext{
General rights

Copyright and moral rights for the publications made accessible in the public portal are retained by the authors and/or other copyright owners and it is a condition of accessing publications that users recognise and abide by the legal requirements associated with these rights.

\section{Take down policy}

If you believe that this document breaches copyright please contact us (research.lib@cbs.dk) providing details, and we will remove access to the work immediately and investigate your claim.
} 


\section{Short sales, price pressure, and the stock price response to convertible bond calls}

K. Bechmann 


\title{
Short sales, price pressure, and the stock price response to convertible bond calls
}

\author{
Ken L. Bechmann ${ }^{a}$ \\ Department of Finance \\ Copenhagen Business School
}

\section{Current version: November 25, 2003}

Key words: Convertible bond calls; Hedging; Short selling; Price pressure; Underwriting

JEL Classification: G14; G24; G32

a Solbjerg Plads 3, DK-2000 Frederiksberg, Denmark

Phone: +4538152953 Fax: $+4538153600 \quad$ e-mail: kb.fi@cbs.dk

The author is especially grateful to Bruce D. Grundy, Bruce N. Lehmann, A. Craig MacKinlay, Kristian Rydqvist, René M. Stulz, and an anonymous referee for many helpful comments. The author also owes thanks to Bent Jesper Christensen, Günter Franke, Per Hiller, Peter Løchte Jørgensen, Ricardo Leal, Johannes Raaballe, Richard Stapleton, and the participants in the Corporate Finance Discussion Group at the Wharton School, the EIASM/EFA Doctoral Tutorial, the FMA-EFMA Conference, the EFA Conference, the Finance Seminars at the University of Aarhus, at the Copenhagen Business School, and at the Stockholm School of Economics. Sophia Barkat and Ariel Rothman provided excellent research assistance. Convertible bond investors at Salomon Brothers, Smith Barney, County NatWest, and Credit Suisse First Boston helped with many details about the convertible bond market. Financial support was provided by the Geewax-Terker Research Program in Financial Instruments (through the Rodney L. White Center, University of Pennsylvania), and the Aarhus University Research Foundation. 


\title{
Short sales, price pressure, and the stock price response to convertible bond calls
}

\begin{abstract}
The announcement of a convertible bond call is associated with an average contemporaneous abnormal stock price decline of $1.75 \%$ and an ensuing price recovery in the conversion period. A price fall and the subsequent recovery suggest price pressure as the explanation for the announcement effect. However, in a perfect capital market the option to convert is not exercised early and hence, the increase in the number of shares outstanding does not occur at the announcement date. Instead, this paper argues and provides evidence that hedging-induced short selling is causing at least part of the short-run price pressure.
\end{abstract}

Key words: Convertible bond calls; Hedging; Short selling; Price pressure; Underwriting

JEL Classification: G14; G24; G32

\section{Introduction}

The announcement of an 'in-the-money' convertible bond call is associated with an average contemporaneous abnormal stock price decline of $1.75 \%$ and an ensuing price recovery in the conversion period. This paper argues and provides evidence that the decline in stock prices is due to investors' short selling of the underlying stock at or around the call announcement. Two types of investors have incentives to hedge their equity exposure by short selling at the time of the call. First, the convertible hedge desks of investment banks try to lock in arbitrage profits by buying the called convertible bond and short selling the underlying stock. Short selling is used to hedge the equity risk of the convertible bond because the option to convert is not exercised immediately. Second, a possible underwriter of the call also short sells in order to hedge the equity risk associated with the call. The short selling of stock by these two types of investors, at least in part, causes the short-run price pressure.

In order to provide evidence for such hedging, this paper contains the first analysis of short selling around calls of convertible securities. More precisely, this paper examines the relationship between short selling, trade volume, the predictability of the call, the stock price reaction to the call announcement as well as variables related to hedging. 
This paper shows that the short selling of stock increases in anticipation of the call and that during the conversion period, the number of shares sold short is more than three times higher than after the call. On average, the total short selling involves at least $19 \%$ of the new shares to be issued upon conversion, which corresponds to nearly 14 days of trading based on the average trade volume before the call. In addition, the paper provides evidence of a large increase in the trade volume at the announcement of the call, and shows that this trade volume is related to the number of new shares to be issued upon conversion of the bonds. Such an increase in trade volume, at least partly due to short selling, is likely to depress stock prices, thus causing the short-run price pressure around convertible bond calls. Furthermore, the paper shows that short selling is not solely caused by a possible underwriter. Finally, the paper shows that the relationship between the announcement effect and several variables describing the call is also consistent with a hedging-induced price pressure.

The case of convertible bond calls and the related findings are important for at least three reasons. First, the arguments and findings presented in this paper close a gap in the existing explanations for the negative announcement effect of convertible bond calls first documented by Mikkelson (1981). Harris and Raviv (1985) provide a theoretical model that explains why the call might work as a signal revealing bad news about a firm's prospects. However, the empirical evidence does not seem to support this bad-news explanation. ${ }^{1}$ Instead, Mazzeo and Moore (1992) document a recovery of stock prices during the conversion period. Based on this and other tests, Mazzeo and Moore argue that the announcement effect is due to price pressure caused by investors wanting to sell the new stock received upon conversion of the bonds. A problem with this argument is that the bonds are not converted at the time of the call announcement, and hence the new shares are not issued until later. The fact that bondholders in general do not hold any of the underlying stocks, shows that Mazzeo and Moore (1992) are missing an explanation about how the later increase in the supply of shares is actually translated into price pressure at the time of the call announcement. The present paper is the first to argue and provide evidence that the price pressure is caused by the short selling of stock.

Second, the discovery of a short selling induced price pressure suggests the importance of liquidity costs and is therefore related to the discussion of downward sloping short-run demand curves

\footnotetext{
${ }^{1}$ See for example Byrd and Moore (1996), Ederington et al. (1997), and Ederington and Goh (2001). Datta et al. (2003) find positive short-run but negative long-run abnormal returns and thus provide some evidence for the bad-news explanation.
} 
for stocks. ${ }^{2}$ Specifically, in this case the price pressure is found to be caused by the rarely examined short selling of stock.

Third, the case of convertible bond calls provides insights into the behavior and investment strategies of highly specialized investment banks. In particular, rather than hedging only systematic risk, investment banks hedge on a deal by deal basis by short selling the underlying stock. Hence, the results of this paper illustrate the importance of understanding investment strategies and behavior by investment banks in order to explain short-run fluctuations in stock prices.

The remaining part of this paper is organized as follows: Section 2 describes calls of convertible bonds and explains how short selling and hedging are related to the calls. Section 3 gives a short description of the methodology and data-set used in this paper. Section 4 presents and discusses the empirical results in four parts: first, an event study documents the negative announcement effect and the subsequent recovery of stock prices. Second, a study of price pressure is presented. Third, short selling is examined in detail, including a study showing how short selling relates to the called convertible bond issue. Finally, the announcement effect is linked to hedging, short selling, and the use of underwriters. A short summary and concluding remarks are given in Section 5 .

\section{Hedging convertible bond calls: Hypothesis development}

\subsection{Calls of convertible bonds}

The owner of a convertible bond has an option to convert the bond into new common stock in the firm. The option to convert is an American style option that matures at the same time as the bond. Besides the conversion option, the majority of convertible bonds also gives the issuing firm a call option, making it possible to redeem the bonds prematurely. The firm redeems the bonds by sending a notice of redemption (the call announcement) to each bondholder. In the notice of redemption, the firm offers to buy each bond for the call payment. The call payment (or the effective call price) is the sum of the interest accrued since the last interest payment and the call price specified in the bond indenture. The announcement of the call starts the conversion period (or notice period) in which each bondholder still has the option to convert into stock. The notice of redemption states the deadline for conversion as well as the call date (redemption date) when unconverted bonds are redeemed and corresponding call payments are made.

\footnotetext{
${ }^{2}$ See Kraus and Stoll (1972), Harris and Gurel (1986), Shleifer (1986), Hansen (1988), and Kaul et al. (2000). A recent paper documenting the existence of a temporary price pressure is D'Mello et al. (2003).
} 
The calls considered in this paper are conversion forcing (or in-the-money) calls. This means that the conversion value, i.e. the value of the shares that would be received upon conversion, is higher than the call payment at the time of the call. Therefore, if a bondholder has to choose whether or not to convert on the day of the announcement, it is optimal to convert into stock.

Figure 1 presents a time-line for convertible bond calls. It also summarizes the trades of the different players involved in convertible bond calls. These players and their trades are explained in detail in the following subsection.

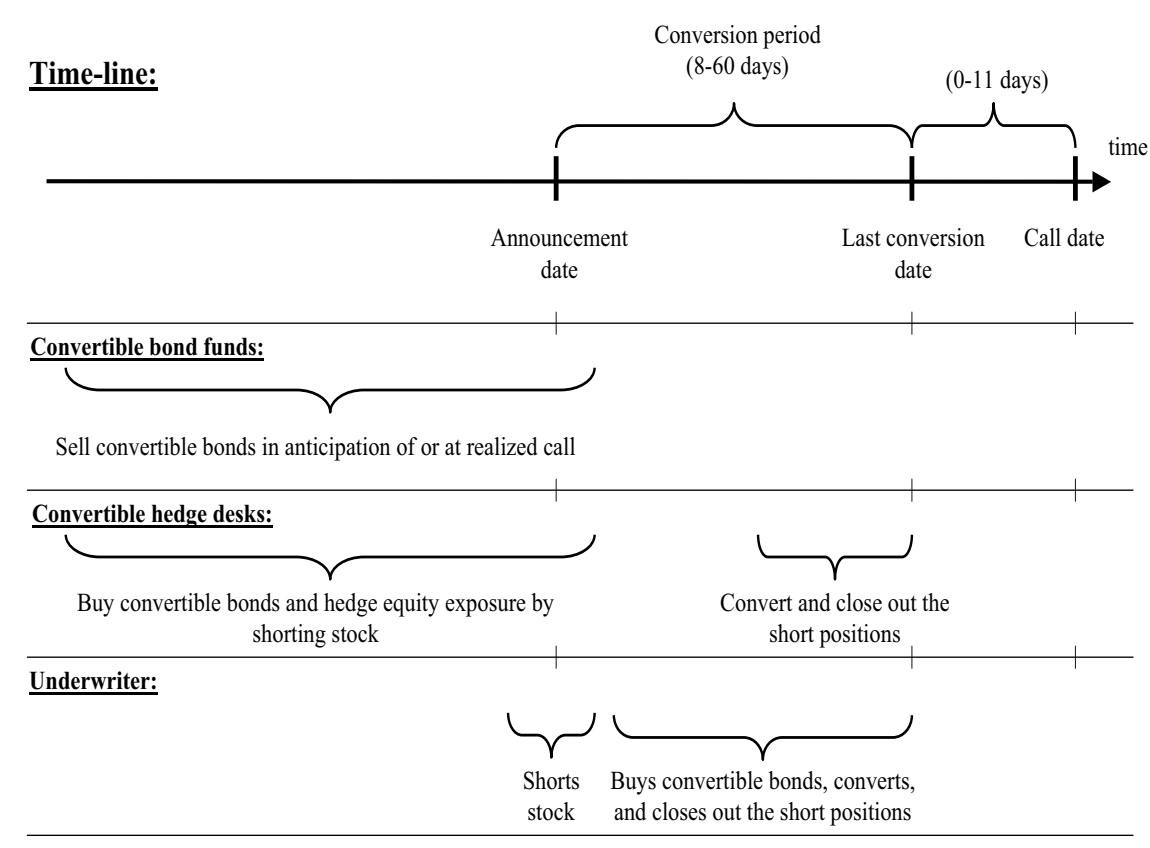

Figure 1: Time-line and trades of the different players involved in convertible bond calls. The number of days between the different dates have been taken from the sample of calls of convertible bonds described in Subsection 3.2 and are stated in trading days.

\subsection{Short selling and hedging}

The original holders of convertible bonds such as convertible bond funds react to anticipated and realized calls by selling their bonds. At least three factors may cause this selling behavior. First, there are limits to the amount of equity risk these convertible bond funds are allowed to take. Second, it may simply be that a call eliminates the characteristics of the convertible bond, such as a conversion option with a long time to maturity, which caused the funds to buy the bonds in the first place. Thereby, an anticipated or realized call often makes the bonds unattractive to these 
funds. Finally, the original holders may not want or are not allowed to hold the stock after the call and therefore see no reason to deal with the practical matters related to the conversion itself. ${ }^{3}$

The buyers of convertible bonds are the convertible hedge desks of investment banks. Convertible hedge desks hedge their equity exposure by shorting stock. ${ }^{4}$ Therefore, the number of shares sold short is expected to increase in the period before and at the call announcement as the convertible hedge desks buy bonds. Moreover, at the time of the call there will be an additional effect on short selling since the hedge ratio for the convertible bonds already held by the desks increases. This increase in the hedge ratio leads to an additional increase in the number of shares sold short for hedging purposes.

Even after a convertible bond has been called, the conversion option is still valuable. As with standard American call options, it is generally optimal to delay the conversion as long as possible, i.e. until the end of the conversion period. Therefore, the number of shares sold short is expected to remain high during the conversion period. Only later when the hedge desks find it optimal, do they convert the bonds and use the shares received to close out their short positions. However, factors such as dividend payments in the conversion period and the costs associated with maintaining the hedging position can make it optimal to convert early. Consequently, these factors can lead to conversions early in the conversion period, which, of course, influence the short selling pattern.

Underwriters of convertible bond calls also have an incentive to hedge their equity exposure. An underwriter guarantees that the called bonds are converted into new stock in the firm. The underwriter does this by paying the call payment to those bondholders who do not convert and by buying the corresponding stock from the firm. As in the case of convertible hedge desks, the underwriter can hedge the equity exposure by short selling stock which is then denoted as a lay-off sale. ${ }^{5}$ The underwriters may, in contrast to the convertible hedge desks, have an incentive to buy bonds during the conversion period and convert them into stock immediately. Such an incentive exists if the underwriter wants to reduce the equity exposure as soon as possible. The incentive to buy bonds in the market is even stronger when the underwriter is paid a take-up fee for each

\footnotetext{
${ }^{3}$ While it is not the purpose of this paper to explain the behavior of the original bondholders, the managers of convertible bond funds and convertible hedge desks assured us that the original holders typically sell the bonds in anticipation of or at realized calls. For example, the fraction of newly issued shares owned by the original bondholders after conversion is estimated to be less than $20 \%$.

${ }^{4} \mathrm{~A}$ similar investment strategy in the case of convertible preferred stocks is examined in Howe et al. (1998), where evidence is provided that hedge desks buy the called convertible preferred stock and hedge the associated risk by short selling the underlying stock.

${ }^{5}$ Underwritten calls of convertible bonds share similarities with underwritten rights offers. Singh (1997) examines underwritten rights offers and finds that underwriters purchase rights hedged with the short sale of common stock in the rights-offering period.
} 
bond they convert into stock. Furthermore, this is also consistent with the general perception in the convertible bond market that underwriters are actively buying up bonds at prices higher than what other market participants (hedge desks) are willing to pay. ${ }^{6}$ Finally, this also suggests two reasons why underwritten calls might be associated with more hedging and thereby more short selling than non-underwritten calls. First, the underwriter may be less diversified and have higher risk exposure to the individual call, and, second, the underwriting fees may make higher hedging costs acceptable to the underwriter.

Based on the above arguments we should expect that the number of shares sold short, and hence also the number of shares traded (the trade volume), are related to the call. The number of shares sold short is expected to increase in the period prior to the call with a peak at the announcement of the call. In addition, the number of shares sold short is expected to decline at the end of the conversion period when the new shares received upon conversion of the bonds are used to close out the short positions. However, the decline in the number of shares sold short may happen before the end of the conversion period if, for example, there are specific reasons for an early exercise of the conversion option. The trade volume and the short selling of stock are examined in subsections 4.2 and 4.3 .

An increase in the short selling of stock explains how the new shares issued upon a later conversion can lead to price pressure at the announcement of the call. Therefore, part of the announcement effect may be caused by investors who - for hedging purposes - short stock as described above. The subsequent price recovery will then follow as the hedging positions are closed out. Short selling leads to price pressure because the price must fall in order to induce investors to absorb the increased supply of shares in accordance with the cost of liquidity. Short selling is often argued to indicate a future excess demand for the stock as the short sellers have to buy shares in the stock market in order to close out their short positions. However, this is not the case when shares are sold short to hedge a convertible bond call. Instead, the short selling is accompanied

\footnotetext{
${ }^{6}$ An article dated April 29, 1996 in the Investment Dealers' Digest describes this type of behavior in the case of an underwritten call of a $\$ 1$ billion convertible bond issue made by AMR Corp. The call was underwritten by five investment banks (CS First Boston, Merrill Lynch, J.P. Morgan, Salomon Brothers, and Goldman, Sachs \& Co.) As underwriters, these investment banks had agreed to buy up to 12.9 million shares if the investors did not convert, eliminating any need for AMR Corp. to come up with cash should the conversion fail. This call is argued to have a high-risk profile not only because of the size of the call, but also because the conversion value is just $12.7 \%$ above the call payment. As the article mentions: "It's one of those deals where the firm's relationship guys are happy, but the risk management side is not happy." The announcement of the call led to a stock price decline of $6.0 \%$, increasing the risk of a failed forced conversion. However, it is also noted in the article that: "... the underwriters themselves were causing some of the pressure on the stock, as they aggressively reduced their risk by buying bonds and shorting the stock in the open market. According to one source, only $\$ 400$ million of the risk remained two days after the call announcement." The open market operations both reduced the underwriters' risks and allowed them to receive the take-up fee.
} 
by an expected future increase in the supply. Subsection 4.4 examines the relation between the announcement effect and the short selling of stock.

As previously discussed, short selling is important in connection with convertible bond calls. The Securities and Exchange Commission (SEC) Rule §240.3b-3 defines a 'short sale' as, "any sale of a security which the seller does not own." A holder of a convertible bond is deemed to own the corresponding shares only when the convertible bond has been handed in for conversion. Therefore, it is a short sale if the owner of a convertible bond sells some of the corresponding shares before the bond has been handed in for conversion.

Short sales are regulated in SEC Rule $\S \S 240.10 a-1$ and 240.10a-2. From $\S 240.10 a-1$ (a) it follows that short sales are prohibited when stock prices are declining according to the so-called up-tick rule. More precisely, the up-tick rule states that short sales are only permitted at a higher price than the preceding transaction of the same stock (an up-tick) or at the same price as the previous transaction, but at a higher price than the last difference price (a zero-plus-tick). However, there are important exemptions from this rule. SEC Rule $\S 240.10 \mathrm{a}-1(\mathrm{e})$ states that the up-tick rule does not apply (i.e. you can short sell exempt from the up-tick rule) if you either own a convertible bond or if you are making a lay-off sale in connection with a standby underwriting commitment. This means that even though stock prices are declining, it is possible for convertible hedge desks, who own convertible bonds, and for underwriters to short sell the corresponding stock. These two exemptions from the up-tick rule are clearly important in the case of convertible bond calls because the call announcement is, on average, associated with declining stock prices, as shown below.

\section{Methodology and data}

\subsection{The methodology}

A standard event study is used to derive the pattern of abnormal stock returns in a period around the call announcement. ${ }^{7}$ An estimation period from 150 to 300 days after the announcement is used in order to avoid the selection bias caused by the use of a pre-event estimation period. ${ }^{8}$ This period is used to estimate the normal return parameters according to the market model with the CRSP

\footnotetext{
${ }^{7}$ The event study used is as described in Campbell et al. (1997), but some of the tests used in this paper are different from the tests described there as we would like to test for the significance of abnormal returns over conversion periods with different lengths. A test taking this into account is described, for example, in Mikkelson and Partch (1988).

${ }^{8}$ Because convertible bonds are typically issued with a conversion option deep out-of-the-money, stock prices should increase before it is possible for the firm to force conversion by calling the bond. Hence, the use of a pre-event estimation period biases the so-called normal returns used in the event study and therefore, a post-event estimation window should be used.
} 
equally weighted index as the market index. The event study has also been performed using other methods to calculate the excess returns with other estimation periods, with the constant return model, and with the value-weighted index as market index. In all cases the results are similar to the main findings in the next section as long as a post-event estimation period is used.

\subsection{The data-set of convertible bond calls}

The data-set consists of complete calls of convertible bonds in the period 1963-1995. Standard and Poor's Bond Guide and Moody's Bond Guide have been used to identify the calls. ${ }^{9}$ From this set of calls, those fulfilling the following selection criteria were selected:

- An announcement date can be identified in either the Wall Street Journal or through the Lexis-Nexis/Dow Jones news wires. ${ }^{10}$

- Information about the firm's stock is available on the CRSP-file.

- The conversion value is higher than the call payment at the time of the announcement. ${ }^{11}$

These selection criteria lead to a sample of 380 calls distributed over time as Table 1 illustrates. Though there are relatively few observations in the beginning of the time period, there is no severe clustering of observations. Furthermore, as we are interested in how stock prices are affected by the call, it is necessary to exclude observations where other news is announced at the time of the call. Finally, in order to apply the event study, stock returns have to exist for a period around the call announcement and during the estimation period. Therefore, in connection with the event study we furthermore require that:

- No other news about the same firm appears in the Wall Street Journal from one day before to one day after the announcement date.

- Daily stock returns are available on the CRSP-file from 50 days before the call to 300 days after the call.

\footnotetext{
${ }^{9}$ An initial set of calls was kindly provided by W. T. Moore.

${ }^{10}$ An extensive news wire search has two advantages. First, it is possible to obtain a much larger sample than those used in other studies of convertible bond calls. Second, news wires make it possible to obtain more accurate announcement dates, which are clearly important when studying the announcement effect. News about the call may be available on news wires a few days before the announcement appears in the Wall Street Journal.

${ }^{11}$ The conversion value is calculated as the stock price two days prior to the announcement multiplied by the conversion ratio (the number of shares each bond is convertible into). The call payment is the payment including the accrued interest that is paid to investors who do not convert into stock.
} 
A total of 71 observations do not satisfy these two requirements, thus the event study only takes the remaining 309 observations into consideration. ${ }^{12}$

Table 1: Distribution over time of the sample of 380 convertible bond calls.

\begin{tabular}{|l|ccccccccccc|}
\hline Period & $63-65$ & $66-68$ & $69-71$ & $72-74$ & $75-77$ & $78-80$ & $81-83$ & $84-86$ & $87-89$ & $90-92$ & $93-95$ \\
\hline Calls & 5 & 24 & 23 & 24 & 23 & 46 & 32 & 48 & 60 & 41 & 54 \\
\hline
\end{tabular}

In addition to the announcement date, more detailed information about each individual convertible bond issue is required. Several sources have been used to collect this information. Some of these are Standard \& Poor's Bond Guide, Moody's Bond Guide, Moody's Industrials, the Wall Street Journal, and the Corporate Financing Directory. All information on stock splits, number of shares outstanding, stock prices, stock returns etc. was collected from the CRSP-file.

\section{Summary statistics}

Table 2 provides sample characteristics. From the table, we observe that convertible bond calls in general lead to quite a significant increase in the number of shares outstanding with an average increase of $12.3 \%$ and a median of $9.6 \%$. However, the increase in the number of shares outstanding varies from $0.03 \%$ to $49.60 \%$. The table also shows that the conversion value varies from $1 \%$ to $406 \%$ above the call payment with an average of $47 \%$. These summary statistics indicate that so-called clean-up calls exist in the sample. ${ }^{13}$

The length of the conversion period is on average slightly longer than one calendar month, corresponding to 23.5 trading days. The bonds are typically called many years before maturity, on average more than 16 years. Finally, it should be noted that 115 of the 380 calls are underwritten, corresponding to slightly more than $30 \%$. All in all, the characteristics of the present data-set are similar to characteristics reported for data-sets used in the previously mentioned studies of convertible bond calls.

\footnotetext{
${ }^{12}$ Of the 71 observations, 21 have been removed because of missing data, primarily because the stocks were delisted shortly after the call due to takeovers and acquisitions. Further investigation of these 71 observations shows that their average stock price pattern is not materially different from the remaining 309 observations.

${ }^{13}$ Clean-up calls are calls with the purpose of redeeming a small issue in order to avoid servicing such a small amount of outstanding debt. These calls typically only lead to a small increase in the number of shares outstanding and can have a conversion option deep in-the-money. This is consistent with the fact that the minimum face value of a called issue is only $\$ 147,000$.
} 
Table 2: Descriptive statistics for the 380 convertible bond calls in the period 1963-1995. The increase in the number of shares (millions) is defined as the total number of new shares that would be issued upon a full conversion of the bonds outstanding. The increase in number of shares (\%) is obtained by dividing the increase in number of shares (millions) with the number of shares outstanding before the call. The size of a called issue is the face value of debt outstanding before the call. The conversion value/call payment measures the extent to which the conversion option is in-the-money. The conversion value is calculated based on the stock price two days prior to the announcement of the call. The length of the conversion period is the number of trading days from the announcement of the call until the end of the conversion period. The number of years to maturity is the number of years from the time of the call until the maturity of the bond.

\begin{tabular}{|l|r|r|r|r|}
\hline & Mean & Median & Minimum & Maximum \\
\hline Increase in number of shares (millions) & 2.23 & 1.27 & 0.01 & 20.80 \\
Increase in number of shares (\%) & 12.32 & 9.61 & 0.03 & 49.60 \\
Size of called issue (\$ millions) & 53.53 & 30.00 & 0.15 & 805.00 \\
Conversion value/call payment & 1.47 & 1.32 & 1.01 & 5.06 \\
Length of conversion period (trading days) & 23.52 & 22.00 & 8.00 & 60.00 \\
Number of years to maturity & 16.66 & 18.00 & 1.00 & 27.00 \\
\hline
\end{tabular}

\subsection{The short interest data}

At a given point in time, the number of shares sold short, also called the short interest, is defined as the number of shares that has been borrowed for short sales but not repaid at that time. Unfortunately, the short interest numbers are available only on a monthly basis, and furthermore they have only been available electronically for the last few years. The numbers for this study were collected from Standard $\&$ Poor's Daily Stock Price Record for the NYSE and AMEX. The Daily Stock Price Record reports the short interest numbers for each individual stock on the respective stock exchanges. The numbers are the same as those published monthly in the Wall Street Journal and represent the total number of shares sold short on the last day of trade on or before the 15th of the month. For this study it is important to know the exact date for which the short interest is computed. This is required in order to determine whether additional short selling caused by the call announcement is included in a certain short interest number or not. ${ }^{14}$

\footnotetext{
${ }^{14}$ Due to the settlement period, the exact calculation date for the short interest depends on the length of this period. For example, if the report date (the 15th) in a standard month before June 1995 is a trading day, the short interest will report the number of shares sold short and still not closed out when the stock exchange closes on the 8th. In addition to the complications related to the calculation date, the data from the Daily Stock Price Record is troublesome to work with when collecting short interest numbers. When stock splits or stock dividends occur, it is often necessary to recalculate several of the numbers manually. In addition, simple errors have sometimes been made in either the order of the months or the order of the short interest numbers. In all cases, the numbers have been compared across several books with overlapping time periods in order to ensure accuracy, while some have furthermore been checked by comparing them to the numbers reported in the Wall Street Journal.
} 
The exact calculation day is found for all the individual short interest numbers and the time series of short interest numbers for the individual stocks are defined such that $S I_{-1}$ is the last short interest number before the announcement, whereas $S I_{0}$ is the short interest number, if any, reported between the announcement day and the last day in the conversion period. ${ }^{15}$ The first short interest number after the last day in the conversion period is defined as $S I_{+1}$.

Summary statistics for the short interest numbers are provided in Subsection 4.3, where the short interest numbers are examined.

\section{Evidence for a short selling induced price pressure}

This section examines the data-set of convertible bond calls and the data-set of short interest numbers described in the previous section. Subsection 4.1 provides evidence for the announcement effect and the subsequent recovery of stock prices. Subsection 4.2 considers price pressure further by examining the trade volume around the call announcement and the relation between the trade volume and the number of new shares to be issued upon conversion. Subsection 4.3 examines the short selling of stock around the call announcement. Subsection 4.4 ends the empirical investigation by examining whether the announcement effect can be explained by short selling and other variables expected to be relevant according to the hedging arguments given in Subsection 2.2.

\subsection{The announcement effect and price recovery}

The results from the event study are shown in Table 3. For different event time periods, the table shows the cumulative average abnormal return, $(\overline{C A R})$, and two different tests for $\overline{C A R}=0$ and their corresponding p-values. The test-statistic $Z$ is a parametric test whereas $J$ is a non-parametric sign-test. The announcement period is from day -1 to day 0 , taking into account that many of the announcements occurred one day before the news appeared in the Wall Street Journal. ${ }^{16}$

The results are illustrated in Figure 2. As expected Table 3 and Figure 2 both show that the stocks have high abnormal returns in the period before the call as discussed in footnote 8 . The call announcement leads to a highly significant $-1.75 \%$ abnormal return, but the stock prices recover

\footnotetext{
${ }^{15}$ For six of the calls, there was actually more than one short interest number in the conversion period. For these calls, the first of them is used as $S I_{0}$. One hundred calls did not have a short interest number reported in the conversion period.

${ }^{16}$ For calls where the announcement is from the news wires, the announcement day is the day after the call appears in the news wires in order to be consistent with the announcement dates from the Wall Street Journal. This also solves the problem that these calls may be announced after the stock market has closed in which case a possible effect would only appear the following day.
} 
Table 3: Results from the event study. Date 0 is the announcement date. The last day in the conversion period is denoted by lcvd. $\overline{C A R}$ is the cumulative average abnormal return for the different time periods. $Z$ is the corresponding test statistic for the significance of $\overline{C A R}$ and $J$ is the sign-test for the significance of $\overline{C A R}$. The p-values are calculated based on the fact that both $Z$ and $J$ are asymptotic normally distributed.

\begin{tabular}{|c|r|r|r||c|r|}
\hline Period (event days) & $\overline{C A R}(\%)$ & \multicolumn{1}{|c|}{$Z$} & $\mathrm{p}$-value(\%) & $J$ & p-value(\%) \\
\hline$-50:-2$ & 8.64 & 8.54 & $<0.01$ & 7.90 & $<0.01$ \\
$-1: 0$ & -1.75 & -10.86 & $<0.01$ & -8.93 & $<0.01$ \\
$+1: \operatorname{lcvd}$ & 2.24 & 2.99 & 0.28 & 3.13 & 0.18 \\
lcvd+1:lcvd+50 & 2.03 & 1.76 & 7.77 & 1.31 & 19.07 \\
\hline$-1: \operatorname{lcvd}$ & 0.49 & -0.29 & 77.24 & 0.40 & 69.05 \\
\hline
\end{tabular}

during the conversion period with an abnormal return of $2.24 \%$, significant at the $1 \%$ level. This gives an insignificant abnormal return of $0.49 \%$ in the period from 1 day before the announcement to the end of the conversion period. ${ }^{17}$

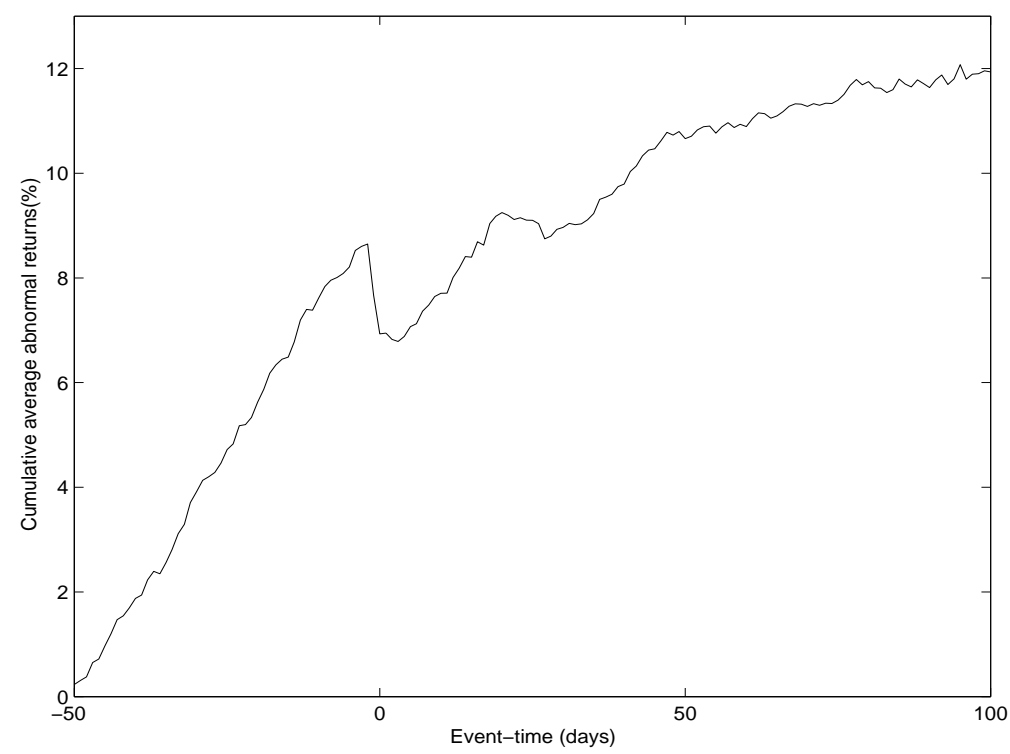

Figure 2: The time pattern in the cumulative average abnormal return $(\overline{C A R})$ from the event study. To estimate the normal returns, a standard market-model is used in a post-event estimation window. Day 0 is the announcement day.

\footnotetext{
${ }^{17}$ It is not obvious during which time period prices are expected to recover given that the stock price pattern is caused by price pressure. This is because the calls may differ regarding the liquidity of the underlying stock, the length of the conversion period, and the amount of short selling that actually occur at the announcement of the call. The conversion period is used here because the short positions are expected to be closed out with new stock issued upon conversion of the bonds during this period.
} 
Figure 2 also gives rise to two additional observations. First, the pattern in abnormal returns suggests the existence of some additional price pressure approximately 25 days after the announcement, corresponding approximately to the end of the average conversion period. This may happen in cases where the equity risk has not been hedged, and hence the shares issued are not used to close out short positions, but rather represent an increase in supply at the end of the conversion period.

The second observation concerns the small positive drift in the period up to 100 days after the announcement. Such a positive drift may suggest the existence of a momentum effect consistent with the fact that many stocks in the sample have significantly positive pre-event stock returns. However, the evidence of a momentum effect is weak. First, based on Table 3 there is only weak evidence for a positive cumulative average abnormal return in the 50-days period after the end of the conversion period. For example, the average cumulative abnormal return is only significantly positive at the $8 \%$ level. Furthermore, only $54 \%$ of the 309 observations experience positive abnormal returns in the period after the end of the conversion period, leading to an insignificant sign-test. Second, as discussed, for example, by Fama (1998), care should be taken when using traditional event studies to evaluate long-run stock effects. In the present case, the findings of an announcement effect and a subsequent stock price recovery are very robust, whereas the long-run stock price pattern is somewhat sensitive to changes in the methodology and the stock market index used. Finally, additional investigation of this issue provides none or only very weak evidence that the recovery can be explained by a momentum effect. In particular, the cumulative abnormal returns for the conversion period are significantly related to the announcement effect and not to pre-event abnormal returns. These results are consistent with findings in the existing literature - see Mazzeo and Moore (1992), Ederington and Goh (2001), and Datta et al. (2003).

We can conclude that stock prices decline at the announcement of a call, but recover during the conversion period. ${ }^{18}$ Thereby, the results confirm earlier research arguing that the short-run pattern in stock prices is caused by price pressure. ${ }^{19}$ The rest of this section provides new evidence of price pressure.

\footnotetext{
${ }^{18}$ Also of potential interest is the pattern in stock price volatility around the event. Based on unreported results, there is no significant change in average volatility from the period before the call to the end of the conversion period. However, the results suggest that average volatility increases in the period after the conversion period. Two interesting explanations may be given for this change. First, it may be that firms primarily make convertible bond calls in periods with low volatility in order to increase the likelihood of a successful conversion of the bonds into stock. Second, it may be that the firm (or management) changes behavior after the convertible bond issue has been converted to stocks.

${ }^{19}$ As the event study is based on daily data, it is possible that the stock price pattern is caused by bid-ask bounce. In results available upon request, we examine this issue in detail using several other tests as well as other data (daily mid-quotes and transactions data). These results confirm the results from the event study.
} 


\subsection{Trade volume and price pressure}

It is often argued that changes in the supply of stocks or the demand for stocks may lead to price effects. In the case of convertible bonds, the new shares are not issued at the announcement of the call. Even if the new shares are not issued at the announcement of the call, the shares can still create price pressure at that time. This is, for example, the case when the holders of convertible bonds hedge against increased equity risk by short selling.

Because the short sale of a share is registered as a trade, an increase in the daily trade volume of the stock is expected around the time of the call announcement. This is examined in Figure 3, which plots the average scaled daily trade volume against event-time. ${ }^{20}$ If an identical number of shares were traded each day, this would give the solid horizontal line shown at 1 in the figure.

From Figure 3 it follows that there is a large increase in the number of shares traded during the time around the call announcement date. The trade volume also appears to be higher than normal in a short period after the announcement. This is consistent with the phenomenon that in a short period after the call announcement investors are still selling convertible bonds to hedge desks, leading to additional short selling and associated price pressure. Figure 2 also suggests the existence of additional price pressure the first few days after the call announcement. In particular, the cumulative average abnormal return for day +1 to +3 is $-0.16 \%$, and it is not until day +5 that stock prices reach a higher level than the level at day 0 .

In Subsection 2.2 it is argued that the increase in short selling (and hence in trading) around the time of the announcement is due to hedging by convertible hedge desks and a possible underwriter. Therefore, we should expect a positive relationship between the trade volume at the time of the call and the number of new shares that would be issued upon conversion of the bonds. As more new shares are issued upon conversion, more shares must be sold in order to hedge the equity risk of the convertible bonds. This relationship is examined by running a regression of the total trade volume for day -1 and 0 (denoted $T R V O L_{i}$ ) on a constant and the number of new shares to be issued (denoted $N e w_{i}$ ), where both numbers of shares are relative to the total number of shares outstanding (denoted $S O_{i}$ ). With this notation, the regression can be written as

$$
\frac{T R V O L_{i}}{S O_{i}}=\beta_{0}+\beta_{1} \frac{N e w_{i}}{S O_{i}}+\epsilon_{i} .
$$

\footnotetext{
${ }^{20} \mathrm{By}$ scaled, we mean that before the average of the trade volumes is calculated, the trade volumes for the individual stocks are divided by their average for the same period, thus preventing stocks with a very high daily trade volume from being too influential. Scaling by the number of shares outstanding, for example, gives a similar figure.
} 


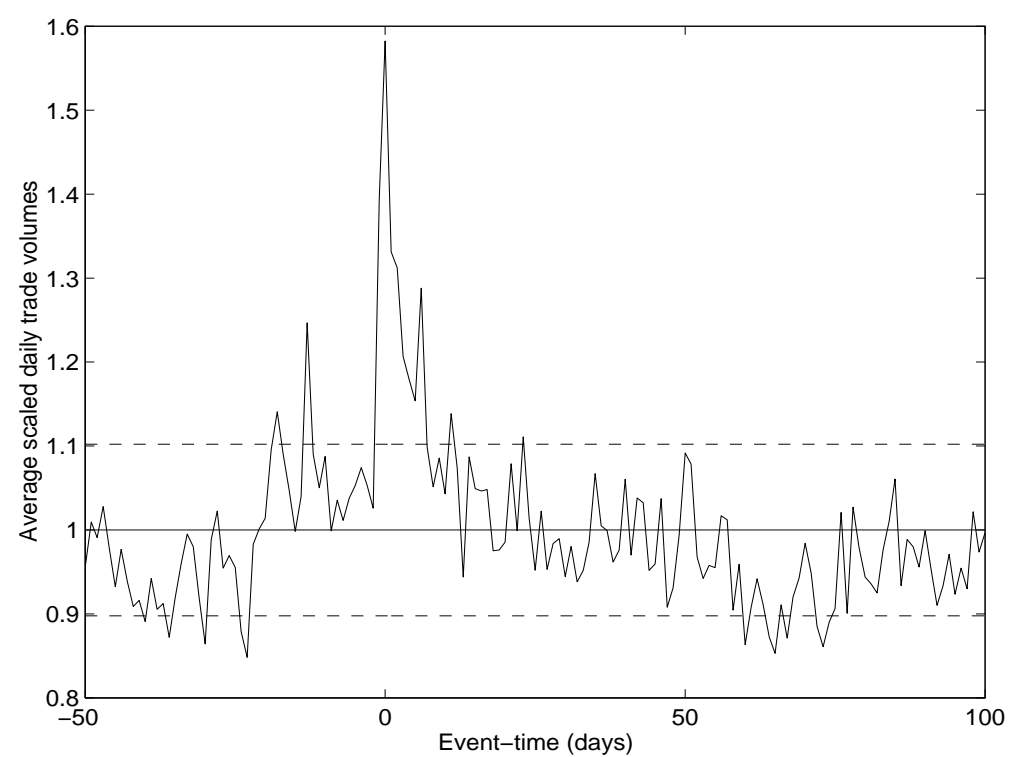

Figure 3: Average scaled daily trade volume with day 0 as the announcement day. The trade volumes for the individual stocks are divided by their mean for the same period. The horizontal line at 1 shows the mean of the average scaled daily trade volumes and illustrates how the pattern would have been if the same number of shares were traded every day. The dashed lines give the one-standard deviation band around the mean.

The results of the regression are (using White's (1980) heteroscedastic consistent errors):

$$
\begin{array}{rlrl}
\hat{\beta}_{0} & =\underset{(0.0011)}{0.0068} & \hat{\beta}_{1} & =\underset{(0.0114)}{0.0511} \\
t & =6.0, p<0.1 \% & t & =4.5, p<0.1 \%
\end{array}
$$

$$
\operatorname{Adj} . R^{2}=12 \% \text {. }
$$

The regression results provide strong evidence for the expected positive relation. On average, the number of shares traded at the call announcement corresponds to more than $5 \%$ of the new shares to be issued. This is consistent with the conjecture that the hedging of equity risk associated with the convertible bond calls causes the trade.

So far, this section has provided evidence for a price recovery as well as evidence that the pattern in stock prices is due to price pressure caused by the call. However, we still need to examine more closely whether the increase in trade volume can be explained by investors' hedging the risk associated with the called convertible bond. Therefore, the next subsection examines whether there is a time pattern in the number of shares sold short and whether the short selling is directly related to the call. 


\subsection{The short interest}

Subsection 2.2 described how short selling is expected to be related to convertible bond calls. First, we should expect that the short selling of stock is related to the call announcement and the importance of hedging. Second, short selling is also expected for calls that are not underwritten. Third, the amount of short selling is expected to be positively related to the size of the call. Finally, we should expect that the announcement effect is related to the amount of short selling. This subsection will examine the first three of these relationships by looking at the monthly short interest numbers. The next subsection examines the relationship between short selling and the announcement effect.

In the previous section, the short interest associated with the call was argued to be $S I_{0}$. However, due to the data available there might be some problems in connection with $S I_{0}$ as a measure of the short selling caused by the call. First, with monthly data and many conversion periods shorter than one month, there are one hundred calls for which no short interest number is available from the conversion period. Therefore, we have chosen to define the short interest $S I_{a t}$ call associated with the call announcement as $S I_{0}$ when $S I_{0}$ is available and $S I_{-1}$ when it is not. Second, as described above, the calculation date for $S I_{0}$ may be close to the end of the conversion period. Finally, as described in Subsection 2.2 there may be reasons for an early close-out of the short positions, which also makes it difficult to measure the additional short selling that occurred at the time of the call. This means that even in the cases where $S I_{0}$ is available, it may be an inadequate measure of the short selling associated with the call. ${ }^{21}$

Table 4 presents summary statistics on the relative sizes of the short interest numbers. Panel A lists the short interest three months before the call $\left(S I_{-3}\right)$, the short interest associated with the call $\left(S I_{\text {at call }}\right)$, and the first short interest number from after the last conversion day $\left(S I_{+1}\right)$ for the whole sample. Panel B focuses on the change in short selling from just before the call $\left(S I_{-1}\right)$ to a point within the conversion period $\left(S I_{0}\right)$ for the sample divided into three groups dependent on this change as well as the availability of $S I_{0}$. In the first three rows of Panel A, the short interest numbers are divided by the number of shares outstanding before the call. In the last three rows of Panel A and in the rows of Panel B, they are divided by the number of new shares to be issued

\footnotetext{
${ }^{21}$ The problems involved with $S I_{\text {at call }}$ suggest using $\max \left[S I_{-1}, S I_{0}\right]$ instead as the short interest associated with the call. All of the following analyses of short selling have been done using this measure. This change of measure did not alter any of the main conclusions, but did improve the level of significance of some of the results.
} 
upon conversion. ${ }^{22}$

From Panel A of Table 4 it follows that the short interest around the call is on average $2.8 \%$ of the total number of shares outstanding and $21.8 \%$ of the new shares to be issued. The amount of short selling varies both relative to the number of shares outstanding and relative to the number of new shares to be issued upon conversion. In both cases, the minimum corresponds to the case where there is no short selling at all. Relative to the number of shares outstanding, the maximum short selling is approximately $30 \%$, while it is approximately $80 \%$ of the number of new shares. The maximum values illustrate that for some calls it is possible that the number of shares sold short stays at a high level even after the conversion period. This indicates that there are probably calls where the short selling of stock is not due to the call alone. Another explanation for short selling around convertible bond calls is that sometimes a call is triggered by a possible merger or acquisition and that some short sellers are speculating in the outcome of such corporate events.

Panel B of Table 4 suggests some interesting differences between the three groups examined. First, the level of short selling is lower for the group that experiences an increased $S I_{0}$ compared to the two other groups. However, the group shows a quite steep increase in short selling, and during the conversion period the average short selling corresponds to more than $22 \%$ of the new shares to be issued. Second, for the group with a decreased $S I_{0}$ there is still quite a significant drop in short interest from $S I_{0}$ to $S I_{+1}$. This suggests that even though there seems to be measurement problems or reasons for converting early, average short selling during the conversion period still involves more than $15 \%$ of the new shares to be issued. Finally, it is worth noting that large calls are more frequent in the group with an increase in short selling than in the two other groups. We will return to several of these differences later and show that they, at least partly, are related to the incentives to hedge.

All in all, Table 4 indicates that the pattern in the short interest numbers is related to the call. There is an increase in short selling before the call and a large decline after the conversion period. As the decline in the short interest is so pronounced from around the call to the subsequent month, the short selling seems primarily associated with the call itself and not with other corporate events. The following will examine this time pattern in further detail.

\footnotetext{
${ }^{22}$ When dividing by the number of new shares, we restrict the analysis to the calls that lead to an increase of at least $2.5 \%$ in the number of shares outstanding, i.e. we exclude clean-up calls. This avoids the problem that might exist when the short interest is divided by a small number of new shares to be issued. One example is a call that leads to only 19.000 new shares being issued. For this call, the short interest is around 2 million shares corresponding to more than one hundred times the number of new shares to be issued. In addition, the pattern in the short interest for this firm seems completely unaffected by the call.
} 
Table 4: Descriptive statistics for the short interest data for the 380 convertible bond calls in the period 1963-1995 and the corresponding tests for changes in the short interest around the calls. The first three rows in Panel A measure the short interest relative to the total number of shares outstanding, $S O$, while the last three rows in Panel A and the rows in Panel B measure the short interest relative to the number of new shares, New, to be issued upon a full conversion of the bonds. The $t$-tests in Panel A test if there is a difference between the short selling at the time of the call $\left(S I_{\text {at call }}\right)$ and the short selling in month -3 $\left(S I_{-3}\right)$ and in month $+1\left(S I_{+1}\right)$ respectively. The $t$-test is the standard one-sided test for the difference between means using matched pairs. In order to avoid scaling problems when dealing with the low number of new shares arising from small calls, it is necessary to set a minimum increase of $2.5 \%$ in the number of shares outstanding when dividing by the number of new shares to be issued. This reduces the number of calls to 327. Panel B, which shows the mean and median short interest for these 327 observations, is divided into three groups: 1) Increased $S I_{0}$ includes observations with an increase from $S I_{-1}$ to $\left.S I_{0}, 2\right)$ Decreased $S I_{0}$ includes observations with a decrease from $S I_{-1}$ to $S I_{0}$, and 3) $N o S I_{0}$ includes observations without a short interest number for month 0 . The numbers of observations in the three groups are 131, 110 and 86 .

Panel A

\begin{tabular}{|c|r|r|r|r|r|r|}
\hline & Mean (\%) & Median (\%) & Min. (\%) & Max. (\%) & \multicolumn{1}{c|}{-test } & p-value (\%) \\
\hline$\frac{S I_{-3}}{S O}$ & 2.13 & 1.06 & 0.00 & 30.30 & 1.61 & 5.41 \\
$\frac{S I_{\text {at call }}}{S O}$ & 2.80 & 1.34 & 0.00 & 33.01 & & \\
$\frac{S I_{+1}}{S O}$ & 1.05 & 0.43 & 0.00 & 10.86 & -10.31 & $<0.01$ \\
\hline \hline$\frac{S I_{-3}}{\text { New }}$ & 15.94 & 9.29 & 0.00 & 77.45 & 2.71 & 0.35 \\
$\frac{S I_{\text {at call }}}{\text { New }}$ & 21.80 & 12.97 & 0.00 & 89.81 & & $<0.01$ \\
$\frac{S I_{+1}}{\text { New }}$ & 7.88 & 3.90 & 0.00 & 63.34 & 18.60 & $<$ \\
\hline
\end{tabular}

Panel B

\begin{tabular}{|c|r|r|r|r|r|r|}
\hline & \multicolumn{2}{|c|}{ Increased $S I_{0}$} & \multicolumn{2}{c|}{ Decreased $S I_{0}$} & \multicolumn{2}{c|}{ No $S I_{0}$} \\
& Mean (\%) & Median (\%) & Mean (\%) & Median (\%) & Mean (\%) & Median (\%) \\
\hline$\frac{S I_{-3}}{\text { New }}$ & 12.60 & 6.98 & 17.39 & 10.71 & 17.60 & 9.75 \\
$\frac{S I_{-1}}{\text { New }}$ & 15.83 & 7.75 & 22.37 & 17.23 & 23.55 & 13.66 \\
$\frac{S I_{0}}{\text { New }}$ & 22.75 & 12.69 & 15.59 & 10.94 & - & - \\
$\frac{S I_{+1}}{\text { New }}$ & 7.69 & 3.45 & 7.55 & 4.28 & 8.18 & 2.51 \\
\hline
\end{tabular}


From Section 2, it follows that several characteristics of the call are expected to influence the bondholders' conversion behavior and hence also the short selling of stock. One main characteristic is related to the conversion option. The incentive to delay conversion and hedge the equity risk is expected to be positively related to the relative importance of the conversion option's time value. To examine this relation and the time pattern in short selling, the data-set is divided into four groups. Group 1 includes the $25 \%$ of the data-set with the highest time-value of the conversion option (calculated using Black and Scholes' (1973) formula) divided by the conversion value; Group 2 includes the next $25 \%$, and so forth. For each of these groups, Figure 4 plots the time pattern of the short interest.

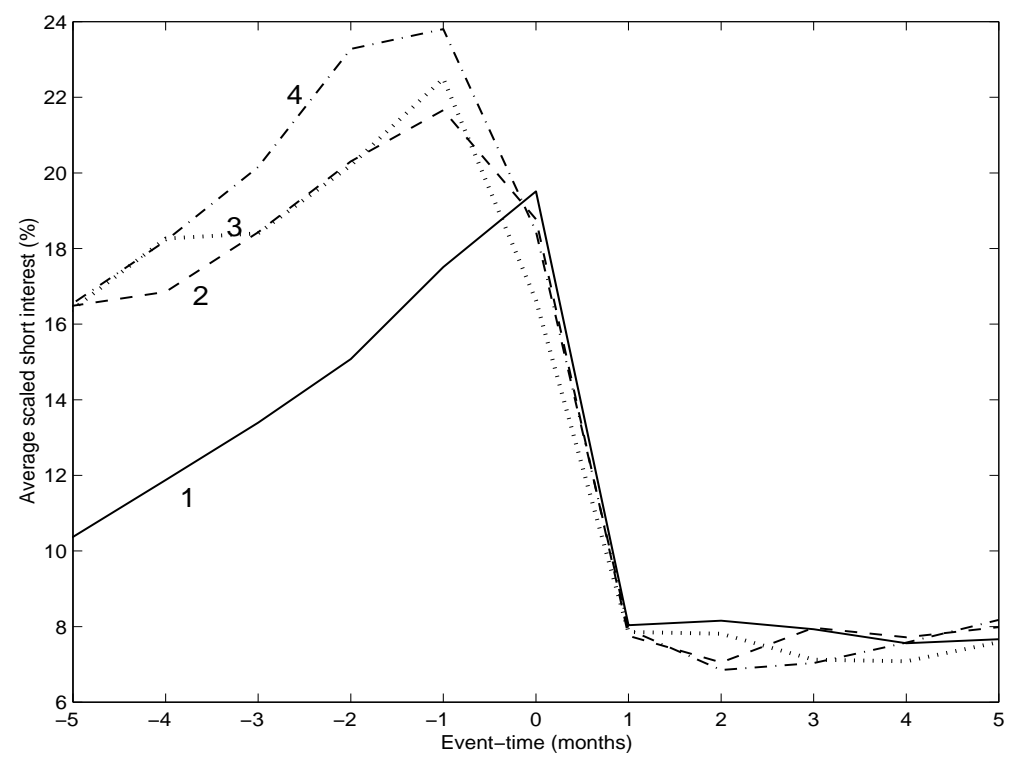

Figure 4: The average scaled short interest for the data-set divided into four groups dependent on the conversion option's time value relative to the conversion value. The time value of the option is calculated using Black and Scholes' (1973) formula. Group 1 has the highest value, while Group 4 has the lowest relative time value. The short interest numbers are divided by the number of new shares to be issued from conversion and therefore, it is again required that $\frac{\mathrm{New}}{\mathrm{SO}}>2.5 \%$.

Figure 4 confirms that the pattern in the short interest numbers is related to the call. In addition, the figure reveals some differences in the time pattern of short interest between the groups. Especially Group 1 stands out with a lower level of short selling in the period before the call. This suggests that calls in this group are less anticipated or that the conversion options have only recently become in-the-money. Furthermore, the four groups are seen to differ with respect to the change in the short interest from month -1 to 0. As described in Subsection 2.2, we should in general expect an increase in short selling from month -1 to month 0 . The reason 
is that the holder of a called convertible bond is expected to delay the conversion until the end of the conversion period. Such a delay in conversion implies that the hedging positions should be maintained until the end of the conversion period, and the increase in short selling associated with the announcement of the call should be seen as an increase from $S I_{-1}$ to $S I_{0}$. Group 1 shows such a clear increase. This is as expected because a conversion option with a relatively high time value should make short selling more pronounced and persistent, and therefore it is more likely that $S I_{0}$ will capture an increase in the short selling at the announcement of the call. These results are also consistent with the results from Table 4 , Panel $\mathrm{B}$, in the sense that the group with increased $S I_{0}$ primarily consists of observations with a relatively high time value of the conversion option.

For the other groups in Figure 4, there is actually a decrease in short selling from month -1 to month 0 -, the decrease being most pronounced for Groups 3 and 4 . There may be several reasons why the pattern for these groups is not completely as expected. As mentioned above, one problem is that $S I_{0}$ can be an inadequate measure of the increase in short selling caused by the call, for example, if there are reasons to convert early. Another problem is that the calculation of the average of the short interest numbers for month 0 is based on fewer observations than the other months. This is especially a problem because, as shown in Table 4, Panel $\mathrm{B}$, the group missing $S I_{0}$ has a relatively high level of short selling before the call.

Table 5 presents a more detailed examination of the changes in the short interest from Figure 4. For the calls with a short interest number for month 0 , the table presents the number of calls with $S I_{0}>S I_{-1}$ and the number of calls with $S I_{0}>S I_{+1}$ for the four groups and the total sample. The table confirms the pattern in Figure 4. Only Group 1 has a significant increase in the short interest number from month -1 to month 0 . However, for the other groups, approximately half of the short interest numbers are seen to increase even though Figure 4 indicates a large decline from month -1 to month 0 . The decline in short selling from month 0 to month +1 is clear and highly significant for all groups. If, due to measurement problems, the large decline observed between $S I_{0}$ and $S I_{+1}$ for some calls occurs between $S I_{-1}$ and $S I_{0}$, then this is a possible explanation for the overall decline in the average for three of the four groups in Figure 4.

These results provide strong evidence that the time pattern in the short selling of stock is related to the call and that anticipated or realized calls lead to an increase in the number of shares sold short. Furthermore, after the end of the conversion period there is a large decrease in short 
Table 5: Comparison of the short interest around the calls for the total data-set and for the data-set divided into four groups dependent on relative importance of the conversion option as measured by the conversion option's time value (calculated using the Black and Scholes' (1973) formula) divided by the conversion value. Group 1 has the highest relative time value, while Group 4 has the lowest relative time value of the conversion option. Calls without any short interest for month 0 are excluded. \#Obs refers to the number of observations in the different groups. Bin-prob is the probability of drawing at least the observed number of increases under the binomial distribution with probability 0.5 and \#Obs trials.

\begin{tabular}{|c|c|r||c|c|}
\hline Group (\#Obs) & $\# S I_{0}>S I_{-1}$ & Bin-prob & $\# S I_{0}>S I_{+1}$ & Bin-prob \\
\hline $1(70)$ & 49 & $<0.1 \%$ & 64 & $<0.1 \%$ \\
$2(70)$ & 38 & $37.5 \%$ & 64 & $<0.1 \%$ \\
$3(70)$ & 26 & $98.9 \%$ & 63 & $<0.1 \%$ \\
$4(70)$ & 28 & $96.4 \%$ & 50 & $<0.1 \%$ \\
\hline All (280) & 141 & $47.6 \%$ & 241 & $<0.1 \%$ \\
\hline
\end{tabular}

selling. ${ }^{23}$ This evidence not only supports the hedging-induced price pressure explanation given in this paper, but also provides new and strong evidence against the bad-news explanation, adding to the evidence presented in, for example, Ederington and Goh (2001). If a convertible bond call was viewed as bad news about the firm, we should have expected a more permanent increase in short selling after the call rather than the observed decrease.

In general, an underwriter will not be appointed until just before the call, and hence, is expected to short sell in only a relatively short period around the call. Therefore, the time pattern indicates that short selling is not alone caused by an underwriter. ${ }^{24}$ To examine this further, we have performed several tests for the relationship between short selling and whether the call is underwritten or not. None of these tests provided any evidence for a significant relationship between the amount of short selling and underwriting. These results are consistent with the argument that convertible hedge desks are also short selling stock in connection with convertible bond calls.

Having demonstrated that the time pattern in short selling is related to the call, we will now

\footnotetext{
${ }^{23}$ Here it can be noted that stock options provide an alternative means by which equity exposure can be hedged. Slightly more than $10 \%$ of the sample of calling firms have stock options traded. The trade volume of these options has been examined using options data from the CBOE. Interestingly, the pattern in trade volume for this small sample of firms is quite consistent with the time pattern in the short selling of stock. The trade volume increases during the period before the call announcement and decreases during the conversion period. Furthermore, there is some evidence of abnormal trading volume on the announcement date and the subsequent days.

${ }^{24}$ This is important because Singh et al. (1991) show that the negative announcement effect is most pronounced for underwritten calls. Thus, one explanation consistent with this finding could be that only underwriters are short selling.
} 
examine whether the number of shares sold short is related to the called bond. First of all, we should expect a positive relationship between the short interest and the size of the call. The size of the call is again measured by the number of new shares that would be issued if all bonds outstanding were converted. $S I_{a t}$ call is again used as the short interest number for the call. However, as we are only interested in the increase in the short interest caused by the call, the short interest in month +1 is subtracted. This is done under the assumption that the short interest number in month +1 represents the normal level due to other reasons for short selling. ${ }^{25}$ In order to examine the relationship between the short interest and the number of new shares to be issued, the following regression is run:

$$
\frac{\left(S I_{\text {at call }}-S I_{+1}\right)_{i}}{S O_{i}}=\beta_{0}+\beta_{1} \frac{N e w_{i}}{S O_{i}}+\epsilon_{i}
$$

where $S O_{i}$ and $N e w_{i}$ are as defined earlier. The results of the regression are (using White's (1980) heteroscedastic consistent errors):

$$
\begin{array}{cc}
\hat{\beta}_{0}=\underset{(0.0023)}{0.0019} & \hat{\beta}_{1}=\underset{(0.0264)}{0.1918} \\
t=-0.59, p=55 \% & t=6.92, p<0.1 \% \\
\text { Adj. } R^{2}=26 \% . &
\end{array}
$$

These results show a highly significant positive relationship between the short interest at the time of the call and the new shares to be issued. From the regression, we obtain the interesting result that the total number of shares sold short on average corresponds to at least $19 \%$ of the new shares. ${ }^{26}$

The above has provided evidence for a significant positive relationship between trade volume around the call and the new shares to be issued (regression (1)) and between short selling in connection with the call and the new shares to be issued (regression (2)). Hence, indirectly this also provides evidence for a positive relationship between trade volume around the call and short

\footnotetext{
${ }^{25}$ To avoid a possible effect from both the short interest and the number of new shares to be issued being positively related to the number of shares outstanding, we again divide by the number of shares outstanding before the call. Similar results are obtained if $S I_{+1}$ is not subtracted, or if we do not divide by the number of shares outstanding.

${ }^{26} \mathrm{~A}$ closer look at the data also reveals a large cross sectional variation in the amount of short selling, as also suggested by Table 4 . This may be caused by several factors. First, the monthly data on the short interest do not perfectly measure the short interest associated with the call. Second, for calls with a high fraction of new shares relative to the shares outstanding, it may be difficult to borrow the shares required in order to short sell. Thus, for large calls, there may not be as much short selling as expected. Finally, it may of course be the case that not all convertible bondholders react to a call as explained in this paper. There may, for example, be convertible bond issues where the original bondholders do not sell the convertible bonds when the call is announced, but instead keep the new shares received from the conversion. There may also be private placements where the convertible bonds are not traded and hence, should not be expected to have the same pattern in short selling for these calls.
} 
selling in connection with the call. For a more direct test of the relationship, we run a regression of trade volume around the call on the change in short selling from month -1 to month 0 , both divided by the number of shares outstanding. Running this regression, including all 280 observations with a short interest number for month 0 , provides no evidence for a significant relationship between the two. However, if the regression is restricted to include only the 141 observations with an increase from month -1 to 0 , the relationship is positive and significant at the $10 \%$ level.

\subsection{Hedging and the announcement effect}

So far, evidence has been provided for a negative announcement effect, a subsequent price recovery, and for a relationship between short selling and the call. A final step is to examine whether the announcement effect can be explained by hedging. One issue to examine is the relation between the announcement effect and the increase in short selling. However, we again encounter problems with availability as well as measurement errors with regard to short interest numbers for month $0 .{ }^{27}$ In an attempt to avoid these problems, we can instead use $S I_{-1}$ as a measure of the short selling that has occurred already before the announcement. In this case, a positive relation between the announcement effect and $S I_{-1}$ should be expected. This is because a lot of short selling before the call implies only little additional short selling at the announcement and hence a less negative announcement effect. One case where $S I_{-1}$ is expected to be high is when the call is anticipated by the market. The reason is that the increased equity risk of the convertible bond would then lead to additional short selling already before the call.

If, as argued in the previous sections, the announcement effect is due to hedging-induced price pressure, it should be expected that several other variables may help explain the cross sectional variation in the announcement effect. First, a large fraction of the new shares to be issued upon conversion relative to the number of shares outstanding is expected to be associated with more price pressure and hence with a more negative announcement effect. This predicts a negative relationship between the announcement effect and the size of the call. Second, in the case of underwritten calls, hedging performed by the underwriter as described in Section 2.2 may lead to additional price

\footnotetext{
${ }^{27}$ As a proxy for an increase in the short interest at the call announcement, we could instead use $S I_{0}-S I_{-1}$ for the calls where $S I_{0}$ exists. A cross plot of the announcement effect, $C A R_{-1: 0}$, against the increase in short interest calculated as $\frac{S I_{0}-S I_{-1}}{S O}$ provides only weak evidence for a relation between the short interest pattern and the announcement effect. There is only evidence for the expected negative relation between the announcement effect and the increase in the short interest for calls with an increase in the short interest number from month -1 to month 0 .
} 
pressure, which due to measurement problems may not be captured by the short selling measure. This predicts a negative relationship between the announcement effect and a dummy variable, which is 1 for underwritten calls and 0 otherwise. Third, as examined in Subsection 4.3, there are the three variables used to calculate the time value of the conversion option. These three factors are the extent to which the conversion option is in-the-money, the volatility of the underlying stock, and the length of the conversion period. If the conversion option is deep in-the-money, the incentive to hedge may be weak. Therefore, a positive relationship is expected between the announcement effect and a measure of the conversion value relative to the call payment. Similarly, a higher volatility or a longer conversion period may increase the incentive to hedge. Therefore, the announcement effect is expected to be negatively related to the volatility and to the length of the conversion period. ${ }^{28}$

In order to examine the relation between the announcement effect and the variables described, the following cross sectional regression is run:

$$
C A R_{i,-1: 0}=\beta_{0}+\beta_{1} \frac{\left(S I_{-1}\right)_{i}}{N e w_{i}}+\beta_{2} \frac{N e w_{i}}{S O_{i}}+\beta_{3} U_{i}+\beta_{4} \frac{C V_{i}-C P_{i}}{C P_{i}}+\beta_{5} \hat{\sigma}_{i}+\beta_{6} \text { Length }_{i}+\epsilon_{i}
$$

where $U_{i}$ is an underwriting dummy, which is 1 if the call is underwritten and 0 otherwise. $C V_{i}$ is the conversion value, $C P_{i}$ is the call payment, $\hat{\sigma}_{i}$ is the volatility of stock prices for bond $i$ estimated in the conversion period, and Length $h_{i}$ is the length of the conversion period in years for bond $i$. As before, only observations with $\frac{N e w}{S O}>2.5 \%$ are used in the regression in order to focus on the significant calls. Results from the individual regressions and the joint regression in (3) are given in Table 6 , where the joint regression only includes variables that are significant in the individual regressions.

From rows $1-6$ in Table 6 it follows that except for the insignificant length of the conversion period, the signs on the estimated coefficients are all as predicted by the hypothesis that the announcement effect is caused by a hedging-induced price pressure. The short selling variable $\left(\beta_{1}\right)$, calculated from the monthly data, is significantly positive with a p-value of $1.1 \%$, meaning as expected that additional short selling before the call leads to a less negative announcement effect. The size of the call $\left(\beta_{2}\right)$, the underwriting dummy $\left(\beta_{3}\right)$, and the degree in-the-money $\left(\beta_{4}\right)$ are all also significant with p-values less than $5 \%$. Surprisingly, the volatility $\left(\beta_{5}\right)$ and the length of the conversion period $\left(\beta_{6}\right)$ turn out to be insignificant. Row 7 covers a joint regression, including the

\footnotetext{
${ }^{28}$ The volatility of stock prices estimated in the conversion period has been used as the volatility of stock prices. However, the results are qualitatively the same if, for example, the stock price volatility estimated before the call was used instead.
} 
Table 6: Results from the regression given in equation (3). Short selling before call refers to $\frac{S I_{-1}}{\text { New }}$, Size of call is $\frac{N e w}{S O}$, Underwritten is a dummy which is 1 for underwritten calls and 0 otherwise, Degree in-the-money denotes $\frac{C V-C P}{C P}$, Volatility is $\hat{\sigma}$, Length conv.period is the length of the conversion period in years. $S I_{-1}$ is the short interest number from the month before the announcement, $N e w$ is the number of new shares to be issued upon conversion, $S O$ is the number of shares outstanding before the announcement, $C V$ is the conversion value, and $C P$ is the call payment. $\hat{\sigma}$ is the volatility of stock prices in the conversion period. The numbers in parenthesis are White's (1980) heteroscedastic consistent errors. *, **, and *** denote significance at the $10 \%, 5 \%$, and $1 \%$ levels respectively in the standard test for significance of the estimated coefficients. Only observations with $\frac{N e w}{S O}>2.5 \%$ are used.

\begin{tabular}{|c|c|c|c|c|c|c|c|}
\hline$\underset{\left(A d j . R^{2}\right)}{\operatorname{Row}}$ & $\begin{array}{c}\text { Intercept } \\
\hat{\beta}_{0}\end{array}$ & $\begin{array}{c}\text { Short selling } \\
\text { before call } \\
\hat{\beta}_{1}\end{array}$ & $\begin{array}{c}\text { Size of } \\
\text { call } \\
\hat{\beta}_{2}\end{array}$ & $\begin{array}{c}\text { Under- } \\
\text { written } \\
\hat{\beta}_{3}\end{array}$ & $\begin{array}{c}\text { Degree } \\
\text { in-the-money } \\
\hat{\beta}_{4}\end{array}$ & $\begin{array}{c}\text { Volatility } \\
\qquad \hat{\beta}_{5}\end{array}$ & $\begin{array}{c}\text { Length } \\
\text { conv.period } \\
\hat{\beta}_{6}\end{array}$ \\
\hline $\begin{array}{c}1 \\
(1.7 \%)\end{array}$ & $\begin{array}{l}-0.0220^{* * *} \\
(0.0024)\end{array}$ & $\begin{array}{l}0.0210^{* *} \\
(0.0081)\end{array}$ & - & - & - & - & - \\
\hline $\begin{array}{c}2 \\
(4.8 \%)\end{array}$ & $\begin{array}{l}-0.0114^{* * *} \\
(0.0035)\end{array}$ & - & $\begin{array}{l}-0.0478^{* * *} \\
(0.0159)\end{array}$ & - & - & - & - \\
\hline $\begin{array}{c}3 \\
(2.0 \%)\end{array}$ & $\begin{array}{l}-0.0149^{* * *} \\
(0.0023)\end{array}$ & - & - & $\begin{array}{c}-0.0086^{* *} \\
(0.0038)\end{array}$ & - & - & - \\
\hline $\begin{array}{c}4 \\
(2.6 \%)\end{array}$ & $\begin{array}{l}-0.0224^{* * *} \\
(0.0025)\end{array}$ & - & - & - & $\begin{array}{l}0.0106^{* *} \\
(0.0049)\end{array}$ & - & - \\
\hline $\begin{array}{c}5 \\
(1.4 \%)\end{array}$ & $\begin{array}{c}-0.0113^{* *} \\
(0.0053)\end{array}$ & - & - & - & - & $\begin{array}{c}-0.0155 \\
(0.0145)\end{array}$ & - \\
\hline $\begin{array}{c}6 \\
(0.6 \%)\end{array}$ & $\begin{array}{l}-0.0235^{* * *} \\
(0.0051)\end{array}$ & - & - & - & - & - & $\begin{array}{l}0.0421 \\
(0.0655)\end{array}$ \\
\hline $\begin{array}{c}7 \\
(4.6 \%)\end{array}$ & $\begin{array}{c}-0.0155^{* *} \\
(0.0067)\end{array}$ & - & - & - & $\begin{array}{l}0.0139^{* * *} \\
(0.0045)\end{array}$ & $\begin{array}{c}-0.0270^{*} \\
(0.0156)\end{array}$ & $\begin{array}{c}-0.0138 \\
(0.0673)\end{array}$ \\
\hline $\begin{array}{c}8 \\
(3.1 \%)\end{array}$ & $\begin{array}{l}-0.0189^{* * *} \\
(0.0028)\end{array}$ & $\begin{array}{l}0.0197^{* *} \\
(0.0079)\end{array}$ & - & $\begin{array}{c}-0.0081^{* *} \\
(0.0040)\end{array}$ & - & - & - \\
\hline $\begin{array}{c}9 \\
(8.4 \%) \\
\end{array}$ & $\begin{array}{l}-0.0177^{* * *} \\
(0.0054)\end{array}$ & $\begin{array}{l}0.0177^{* *} \\
(0.0077)\end{array}$ & $\begin{array}{l}-0.0421^{* *} \\
(0.0170)\end{array}$ & $\begin{array}{c}-0.0047 \\
(0.0038)\end{array}$ & $\begin{array}{l}0.0088^{*} \\
(0.0046)\end{array}$ & - & - \\
\hline
\end{tabular}

degree in-the-money $\left(\beta_{4}\right)$, volatility $\left(\beta_{5}\right)$, and the length of the conversion period $\left(\beta_{6}\right)$. In this regression all variables enter with the expected sign and furthermore, the volatility is significant at the $10 \%$ level. Row 8 documents that short selling and the underwriting dummy are both significant at the $5 \%$ level in a joint regression. Row 9 includes all variables that are significant in the individual regressions. Short selling and size are still significant at the $5 \%$ level, whereas the p-value for the degree in-the-money of the conversion option and the underwriting dummy has now increased to $5.9 \%$ and $22.0 \%$ respectively. If the volatility and the length of the conversion period are included in the joint regression, they enter insignificantly without changing the conclusions following from row 9 .

The changes in the level of significance for some of the variables between the individual regressions and the joint regression indicate the existence of multicollinearity in the regression. From regression (2), we already know that there is a positive and significant relationship between short 
selling and the size of the call. Similarly, it turns out that there are several interesting and important correlations between the other variables. For example, underwriting and the degree in-the-money are negatively correlated, while underwriting and the size of the call are positively correlated. The degree in-the-money is positively correlated with stock price volatility and the length of the conversion period, which provides an explanation for the results about the volatility and the length of the conversion period in the regression. A higher volatility or longer conversion period is associated with a deeper in-the-money conversion option. Therefore, the effect on hedging of a higher volatility or a longer conversion period is partly offset by the effect of the conversion option being deeper in-the-money.

All these relationships and the results from the regression provide additional evidence for the importance of risk and hedging in connection with convertible bond calls. In particular, short selling and other variables related to hedging are, at least in part, able to explain the announcement effect.

\section{$5 \quad$ Summary and conclusions}

Convertible bond calls are associated with a negative announcement effect and a subsequent price recovery. In order to explain this stock price pattern this paper has considered the behavior of investment banks around the call. Evidence was provided that convertible hedge desks and a possible underwriter short sell stock at the time of the call as a means of hedging the equity risk associated with the convertible bond.

One major insight of the paper is that the pattern in the number of shares sold short is related to the called convertible bond issue. Furthermore, it was shown that the short selling of stock, at least in part, can explain the pattern in stock prices around the call consistent with a hedginginduced price pressure. For example, the announcement effect was linked to the short selling of stock, to whether the call is underwritten or not, to the size of the call, and to the extent to which the conversion option is in-the-money.

The assertion of hedging by investment banks and the related empirical evidence are important for at least three reasons. First, the results close a gap in the existing literature on convertible bond calls, this paper being the first to explain and provide evidence that short selling translates the later increase in the supply of shares into price pressure at the time of the announcement. Second, the discovery of a short-selling induced price pressure provides additional evidence for the importance 
of liquidity costs. Finally, the results provide new insights into the investment strategies of highly specialized investment banks and how these investment strategies have consequences for the stock price pattern around convertible bond calls.

\section{References}

Byrd, A.K. and W.T. Moore, 1996, On the information content of calls of convertible securities, Journal of Business 69, 89-101.

Black, F. and M. Scholes, 1973, The pricing of options and corporate liabilities, Journal of Political Economy 81, 637-654.

Campbell, J.Y., A.W. Lo and A.C. MacKinlay, 1997, Econometrics of financial markets (Princeton University Press).

Datta, S., M. Iskandar-Datta and K. Raman, 2003, Convertible bond calls: Resolution of the information content puzzle, Working Paper, forthcoming Journal of Financial Intermediation.

D'Mello, R., S.P. Ferris and C.Y. Hwang, 2003, The tax-loss selling hypothesis, market liquidity, and price pressure around the turn-of-the-year, Journal of Financial Markets 6, 73-98.

Ederington, L.H., G.L. Caton and C.J. Campbell, 1997, To call or not to call convertible debt, Financial Management 26, 22-31.

Ederington, L.H. and J.C. Goh, 2001, Is a convertible bond call really bad news?, Journal of Business 74, 459-476.

Fama, E.F., 1998, Market efficiency, long-term returns, and behavioral finance, Journal of Financial Economics 49, 283-306.

Hansen, R.S., 1988, The demise of the rights issue, Review of Financial Studies 1, 289-309.

Harris, M. and A. Raviv, 1985, A sequential signaling model of convertible debt policy, Journal of Finance 40, 1263-1281.

Howe, J.S., J.C. Lin and A.K. Singh, 1998, Clientele effects and cross-security market making: Evidence from calls of convertible preferred securities, Financial Management 27, 41-52.

Kaul, A., V. Mehrotra and R. Morck, 2000, Demand curves for stocks do slope down: New evidence from an index weights adjustment, Journal of Finance 55, 893-912.

Kraus, A. and H.R. Stoll, 1972, Price impacts of block trading on the New York Stock Exchange, Journal of Finance 27, 569-588. 
Mazzeo, M.A. and W.T. Moore, 1992, Liquidity costs and the stock price response to convertible security calls, Journal of Business 65, 353-369.

Mikkelson, W.H., 1981, Convertible calls and security returns, Journal of Financial Economics 9, $237-264$.

Mikkelson, W.H. and M.M. Partch, 1988, Withdrawn security offerings, Journal of Financial and Quantitative Analysis 23, 119-133.

Shleifer, A., 1986, Do demand curves for stocks slope down?, Journal of Finance 41, 579-590.

Singh, A.K., 1997, Layoffs and underwritten rights offers, Journal of Financial Economics 43, 105130.

Singh, A., A.R. Cowan and N. Nayar, 1991, Underwritten calls of convertible bonds, Journal of Financial Economics 29, 173-196.

White, H., 1980, A heteroscedasticity-consistent covariance matrix estimator and a direct test for heteroscedasticity, Econometrica 48, 817-838. 


\section{List of CAF's Working Papers \\ 2003 -}

141. P. Raahauge (January 2003), Empirical rationality in the stock market.

142. F. Bec and A. Rahbek (January 2003), Vector equilibrium correction models with non-linear discontinuous adjustments.

143. P. Reinhard Hansen and A. Lunde (February 2003), Testing the significance of calendar effects.

144. P. Reinhard Hansen and A. Lunde (February 2003), Consistent preordering with an estimated criterion function, with an application to evaluation and comparison of volatility models.

145. C. Christiansen, T. Engsted, S. Jakobsen and C. Tanggaard (February 2003), An empirical study of the term structure of interest rates in Denmark, 1993-2002.

146. C. Christiansen, T. Engsted, S. Jakobsen and C. Tanggaard (February 2003), A chapter on the Danish bond market.

147. M. Shin Jensen and M. Svenstrup (March 2003), Efficient control variates and strategies for Bermudan swaptions in a Libor market model.

148. B.M. Bibby, I.M. Skovgaard and M. Sørensen (March 2003), Diffusion-type models with given marginal and autocorrelation function.

149. K.L. Bechmann and P. Løchte Jørgensen (March 2003), The value and incentives of optionbased compensation in Danish listed companies.

150. G. Peskir (April 2003), On the American option problem.

151. L. Kelly, E. Platen and M. Sørensen (May 2003), Estimation for discretely observed diffusions using transform functions.

152. O.E. Barndorff-Nielsen and N. Shephard (May 2003), Power and bipower variation with stochastic jumps.

153. G. Peskir (May 2003), The Russian option: Finite horizon.

154. A. Frino, V. Mollica and T. Walter (July 2003), Asymmetric price behaviour surrounding block trades: A market microstructure explanation.

155. K. Stegenborg Larsen and M. Sørensen (July 2003), Diffusion models for exchange rates in a target zone. 
156. D. Koulikov (August 2003), Modeling sequences of long memory non-negative covariance stationary random variables.

157. H. Schmidli (August 2003), Modelling PCS options via individual indices.

158. M. Bladt and M. Sørensen (September 2003), Statistical inference for discretely observed Markov processes.

159. O.E. Barndorff-Nielsen and N. Shephard (November 2003), Econometrics of testing for jumps in financial economics using bipower variation.

160. M. Ørregaard Nielsen (November 2003), Spectral Analysis of fractionally cointegrated systems.

161. M. Ørregaard Nielsen, (November 2003), Local empirical spectral measure of multivariate processes with long range dependence.

162. C. Christiansen (November 2003), Volatility-spillover effects in European bond markets.

163. D. Koulikov (December 2003), Long memory ARCH( $\infty)$ models: specification and quasimaximum likelihood estimation.

164. K. Bechmann (December 2003), Short sales, price pressure, and the stock price response to convertible bond calls.

165. M.Y. An, B.J. Christensen and N. Datta Gupta (December 2003), On pensions and retirement: bivariate mixed proportional hazard modelling of the joint retirement of married couples. 
ISSN 1398-6163

Mailing address: University of Aarhus

Telephone:

Fax:

E-Mail:

http://www.caf.dk
$+4589421580$

+4586136334

CAF@cls.dk 